\title{
Tetracycline-regulated Cardiac Gene Expression In Vivo
}

\author{
Glenn I. Fishman, ** Matthew L. Kaplan, * and Peter M. Buttrick \\ ${ }^{*}$ Cardiology Division, Department of Medicine, and ${ }^{\ddagger}$ Department of Molecular Genetics, \\ Albert Einstein College of Medicine, Bronx, New York 10461
}

\begin{abstract}
Tight regulation of foreign genes expressed in vivo would facilitate studies of many biologic processes and would be useful for gene transfer-based therapies. To test the ability of a tetracycline-regulated gene expression system to function in vivo, we directly injected chimeric tet repressor-VP16 transactivator expression plasmids and luciferase target genes into the hearts of adult rats. Cardiac luciferase activity increased over two orders of magnitude in response to small changes in input tetracycline-controlled transactivator DNA. Transactivation was repressed to background levels by subtherapeutic concentrations of tetracycline in a dose-dependent manner. Target gene expression could be rapidly and reversibly controlled by manipulating antibiotic administration. This system may be particularly useful for in vivo studies of gene function or gene therapies where the timing or extent of expression are critical variables. (J. Clin. Invest. 1994. 93:1864-1868.) Key words: heart • luciferase $\cdot$ gene therapy $\bullet$ transactivation $\cdot$ pharmacokinetics
\end{abstract}

\section{Introduction}

The ability to tightly and reversibly control the expression of exogenous genetic elements in vivo would find great utility in studies of gene function as well as in DNA-based gene therapies. External signals could modulate the accumulation of expressed proteins, enabling one to assess their function at varying concentrations or during specific time intervals. Protein abundance could also be regulated to meet specific therapeutic needs. Despite these potential benefits, highly regulated expression of foreign DNA sequences in vivo remains problematic.

The tetracycline resistance operon of Escherichia coli has been exploited to design a highly effective transcriptional regulatory system in cultured mammalian cells (1). A chimeric transactivator, designated tetracycline-controlled transactivator (tTA), ${ }^{1}$ consisting of the DNA and tetracycline binding domains from the bacterial tet repressor (tet $\mathrm{R}$ ) fused to the

Address correspondence to Dr. Glenn I. Fishman, Albert Einstein College of Medicine, 1300 Morris Park Avenue, Bronx, NY 10461.

Received for publication 22 October 1993 and in revised form 21 December 1993.

1. Abbreviations used in this paper: $\mathrm{CAT}$, chloramphenicol acetyltransferase; $\mathrm{CMV}$, cytomegalovirus; tet $\mathrm{O}$, tet operator; tet $\mathrm{R}$, tet receptor; tTA, tetracycline-controlled transactivator; VP16, virion protein 16 .

J. Clin. Invest.

(c) The American Society for Clinical Investigation, Inc. 0021-9738/94/04/1864/05 \$2.00

Volume 93, April 1994, 1864-1868 transactivation domain of herpes simplex virion protein 16 (VP16), markedly stimulates transcription from minimal promoters harboring tet operator (tet $\mathrm{O}$ ) sequences. By virtue of its affinity for tet $\mathrm{R}$, tetracycline competitively inhibits tTA-dependent transactivation.

In this study, we tested the functionality of this system in vivo by directly transferring plasmid DNAs into the hearts of adult rats and studying their behavior in response to systemic tetracycline therapy. The direct cardiac injection technique has recently been shown to specifically transfect cardiac myocytes surrounding the site of DNA injection (2). Here we demonstrate that transcription of target genes harboring tetO sequences can be markedly transactivated by coinjected tTA expression plasmids. The level of transactivation can be regulated over several orders of magnitude by systemic therapy with oral tetracycline. Furthermore, the extent of target gene expression can be rapidly and reversibly controlled by manipulating antibiotic treatment.

\section{Methods}

DNA plasmids. The tTA expression plasmids used in this study included pUHD15-1 and p $\alpha$-tTA, as shown in Fig. 1. pUHD15-1 contains regulatory sequences from the cytomegalovirus (CMV) promoter and enhancer and directs constitutive expression of TTA, as previously described (1). The cardiac-specific p $\alpha$-tTA includes regulatory elements $(-613$ to +32 , relative to transcription initiation) from the rat alpha myosin heavy chain gene (3), a heterologous adenoviral-immunoglobulin splice cassette, an EcoRI-BamHI fragment containing the tTA coding region from pUHD15-1 (1), and a BglII-EcoRI fragment from the human growth hormone gene which includes the polyadenylation signals and $3^{\prime}$ flanking sequence (4). pUHC13-3 has been described previously, and places the firefly luciferase reporter gene downstream of the chimeric tet operon/CMV minimal promoter (1). pRSVCAT expresses chloramphenicol acetyltransferase (CAT) from the Rous sarcoma virus long terminal repeat (5) and was included in all injections to normalize for transfection efficiency.

Plasmid DNAs were constructed and verified according to standard techniques (6). Large-scale plasmid preparations were purified by column chromatography (Qiagen, Inc., Chatsworth, CA), according to the manufacturer's protocol.

Cardiac gene transfer. Cardiac gene transfer was carried out essentially as described previously (7). All studies were carried out using 175-200-g female Wistar rats, which were cared for in accordance with a protocol approved by the Institutional Animal Care and Use Committee. In brief, animals were anesthetized with an intraperitoneal injection of $4 \%$ chloral hydrate. The hearts were then exposed, and a $50-\mu 1$ solution of plasmid DNAs dissolved in $0.9 \% \mathrm{NaCl}$ and $3 \%$ Evans blue dye was administered intramuscularly into the cardiac apices by a syringe (Hamilton Co., Reno, NV) equipped with a 27-gauge needle. Successful delivery of the DNA solution was visualized by the staining of the apical muscle from the Evans blue dye. After gene transfer, the lungs were reinflated by positive pressure ventilation applied through a 
$p \alpha-t T A$
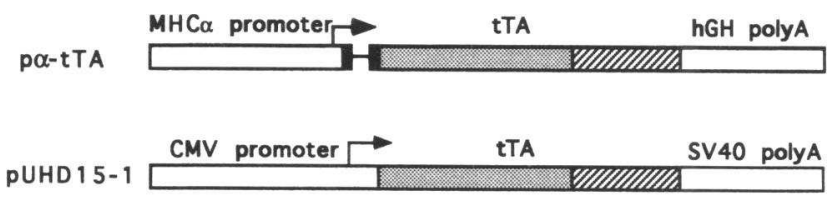

pUHC13-3 $\stackrel{(\text { tetO })_{7} \mathrm{CMV}_{\text {min }} \longrightarrow}{\longrightarrow}$ Luciferase SV40 polyA

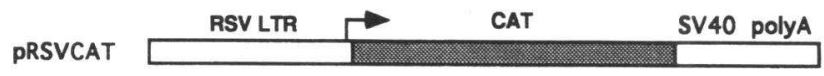

Figure 1. Plasmid constructs. pUHD15-1 includes regulatory sequences from the CMV promoter and enhancer to direct expression of the tetracycline-controlled transactivator. The chimeric protein consists of residues 1-207 from the tet $\mathrm{R}$ protein (stippled) and residues 363-490 from VP16 (cross-hatched). p $\alpha$-tTA replaces the CMV sequences with $5^{\prime}$ regulatory elements from the rat alpha myosin heavy chain gene and substitutes the $3^{\prime}$ end of the human growth hormone gene for SV40 sequences. In addition, a heterologous splice cassette, consisting of adenoviral and immunoglobulin sequences, was inserted into patTA immediately upstream of the tTA coding region. pUHC13-3 places a luciferase reporter gene downstream of the chimeric tet operon/CMV minimal promoter. pRSVCAT expresses CAT from the Rous sarcoma virus long terminal repeat (RSV LTR).

nose cone fitted over the snout of the rat (small animal respirator; Harvard Apparatus, Inc., South Natick, MA). The sternotomy was closed, and the animals were allowed to recover. Mortality from the procedure was $<10 \%$.

Reporter gene assays. Animals were killed at various times after gene transfer, and their hearts were rapidly removed and rinsed in ice-cold PBS. Excess connective tissue, atria, and the base of the ventricles were discarded. The remaining ventricular tissue was homogenized, and luciferase and CAT assays were performed using $50 \mu \mathrm{l}$ of lysate exactly as described previously (7). Luciferase activity was determined using a luminometer (Monolight 2010; Analytical Luminescence Laboratory, San Diego, CA). CAT thin-layer chromatograms were recorded with a phosphor-storage screen, and percentage of CAT conversion was visualized and quantified using a PhosphorImager and associated software (Molecular Dynamics, Inc., Sunnyvale, CA). For each heart, normalized luciferase activity was determined as (total luciferase activity - background)/\% CAT conversion, as previously described (7).

Tetracycline administration. For oral therapy, tetracycline hydrochloride (Sigma Immunochemicals, St. Louis, MO) was prepared as a $0.1 \mathrm{~g} / \mathrm{ml}$ stock in $50 \%$ ethanol and was diluted to the final concentration with $2.5 \%$ sucrose in water. For parenteral therapy, oxytetracycline (LA200; Pfizer Inc., New York) was diluted to $10 \mathrm{mg} / \mathrm{ml}$ with water, and $300 \mu \mathrm{l}$ was injected intraperitoneally. No obvious side effects due to antibiotic therapy were observed.

Tetracycline-dependent repression. $2 \mathrm{~d}$ before cardiac gene transfer, drinking water was replaced with $2.5 \%$ sucrose containing either 1.0 or $0.1 \mathrm{mg} / \mathrm{ml}$ tetracycline hydrochloride or vehicle alone. Hearts were injected with p $\alpha$-tTA $(5 \mu \mathrm{g})$, pUHC13-3 (5 $\mu \mathrm{g})$, and pRSVCAT $(2 \mu \mathrm{g})$ and harvested $5 \mathrm{~d}$ later for determination of luciferase and CAT activities.

Kinetic analysis of tetracycline-regulated expression. To determine the time course of repression, 40 rats underwent direct cardiac gene transfer with p $\alpha$-tTA, pUHC13-3, and pRSVCAT. $5 \mathrm{~d}$ later, half the animals were randomly chosen to receive antibiotic treatment (repressed group) or vehicle alone (control group). Animals in the repressed group received a single dose of oxytetracycline ( $3 \mathrm{mg}$ intraperitoneally) and were started on oral tetracycline therapy $(1 \mathrm{mg} / \mathrm{ml}$ in the drinking water). At subsequent time points, hearts from at least four animals from each group were harvested, and normalized luciferase activity was determined.

To evaluate the time course of gene induction, 40 rats were started on oral tetracycline therapy $(0.1 \mathrm{mg} / \mathrm{ml}$ in the drinking water $)$ beginning $48 \mathrm{~h}$ before cardiac injection. $5 \mathrm{~d}$ after introduction of the DNA, half the rats were randomized to remain on tetracycline therapy (control group), and the other half were switched to vehicle alone (induced group). At subsequent time points, hearts from at least four rats from each group were harvested, and normalized luciferase activity was determined.

Statistical analysis. For each animal, normalized luciferase activity was calculated as described above. Means and standard errors for each group were determined, and differences were assessed using an unpaired Student's $t$ test. $P$ values $<0.01$ were considered statistically significant.

\section{Results}

tTA-dependent transactivation in vivo. The initial set of experiments was designed to assess whether the chimeric bacterialviral tTA transactivator could function within the mammalian cardiac myocyte in vivo. Therefore, mixtures of plasmid DNAs containing the pUHC13-3 luciferase target gene, pRSVCAT, to normalize gene transfer efficiency and varying amounts of tTA expression plasmids were coinjected into the cardiac apices of adult rats. Hearts were harvested $5 \mathrm{~d}$ later for determination of luciferase and CAT activities. As shown in Fig. 2, in the absence of transactivator, only low levels of normalized luciferase activity were detected. Inclusion of $1 \mu \mathrm{g}$ of the cardiac-specific $\mathrm{p} \alpha$-tTA expression plasmid boosted normalized luciferase activity nearly 50-fold $(P<0.0001)$. Higher amounts of tTA expression plasmid progressively increased luciferase activity, reaching a maximum of nearly 125 -fold activation with $10 \mu \mathrm{g}$ of transactivator DNA $(P<0.0001)$.

To compare relative efficacies of viral and cellular promoters, the activity of tTA driven by CMV promoter and enhancer elements was also evaluated. Injection with $2 \mu \mathrm{g}$ of pUHD15-1 resulted in 293,921 $\pm 27,889(n=5)$ normalized

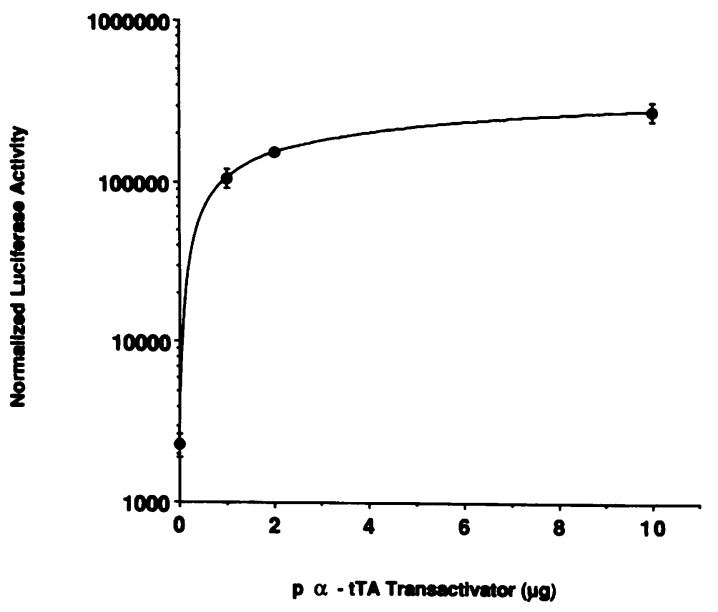

Figure 2. Transactivator-dependent expression in vivo. Mixtures containing pUHC13-3 $(5 \mu \mathrm{g})$, pRSVCAT $(2 \mu \mathrm{g})$, and differing amounts of $\mathrm{p} \alpha$-tTA $(0 \mu \mathrm{g}, n=5 ; 1 \mu \mathrm{g}, n=5 ; 2 \mu \mathrm{g}, n=4$; and $10 \mu \mathrm{g}$, $n=4$ ) were coinjected into the hearts of $175-200-\mathrm{g}$ female Wistar rats in vivo. $5 \mathrm{~d}$ later, normalized luciferase activity was determined. Each data point represents the mean $\pm S E$. Compared with hearts receiving no transactivator, gene transfers including $\mathrm{p} \alpha$-tTA resulted in marked stimulation of luciferase activity $(P<0.0001)$. 
luciferase units, a value twofold greater $(P=0.007)$ than that seen with the same amount of the p $\alpha$-tTA DNA $(152,139 \pm 6,073, n=4)$ and not statistically different from that obtained with $10 \mu \mathrm{g}$ of the cardiac-specific transactivator $(281,618 \pm 39,688, n=4)$.

Inhibition of transactivation by oral tetracycline therapy. We next evaluated whether TTA-dependent reporter gene activity could be inhibited by systemic therapy with tetracycline. Based upon the initial set of experiments, all injections included p $\alpha$-tTA ( $5 \mu \mathrm{g}$ ), pUHC13-3 (5 $\mu \mathrm{g}$ ), and pRSVCAT ( 2 $\mu \mathrm{g})$. Beginning $48 \mathrm{~h}$ before cardiac gene transfer and continuing until the time of killing, drinking water was replaced with $2.5 \%$ sucrose containing either 1.0 or $0.1 \mathrm{mg} / \mathrm{ml}$ tetracycline or vehicle alone. Transactivation of the target gene was markedly repressed by oral antibiotic therapy, as shown in Fig. 3. As little as $0.1 \mathrm{mg} / \mathrm{ml}$ tetracycline added to the drinking water commencing $2 \mathrm{~d}$ before cardiac injection reduced luciferase activity by $90 \%$, compared with vehicle alone $(P<0.001)$. Tetracycline at $1 \mathrm{mg} / \mathrm{ml}$ reduced activity by $97 \%(P<0.001)$, comparable with levels obtained in the absence of the transactivator.

Kinetic analysis of tetracycline-regulated gene expression. The ability to repress or induce target gene expression and the time course of such regulation were also assessed. To determine the rapidity with which transcription could be repressed, systemic tetracycline levels were increased rapidly by treating rats with the parenteral tetracycline analogue, oxytetracycline. As shown in Fig. $4 A$, untreated control animals showed a gradual time-dependent fall in normalized luciferase activity, consistent with the transient nature of this gene transfer technique. In contrast, animals receiving oxytetracycline showed a rapid reduction in normalized luciferase activity, which declined by $60 \% 24 \mathrm{~h}$ after initiating antibiotic treatment $(P<0.01)$ and fell to baseline levels by $48 \mathrm{~h}$.

Conversely, repression of tTA-dependent transactivation was reversed rapidly after discontinuing tetracycline therapy.

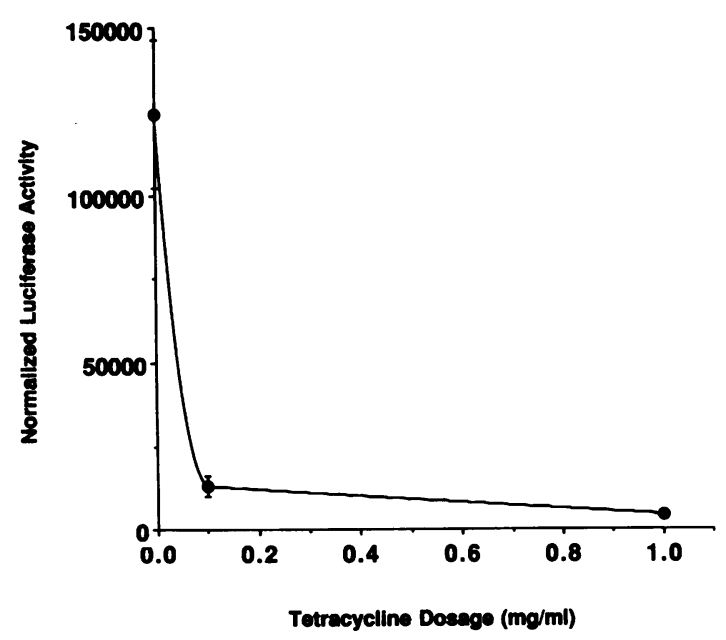

Figure 3. Tetracycline-dependent repression in vivo. $2 \mathrm{~d}$ before cardiac injection, the drinking water was replaced with $2.5 \%$ sucrose containing either $0(n=6), 0.1(n=5)$, or $1.0 \mathrm{mg} / \mathrm{ml}(n=6)$ tetracycline hydrochloride, which was continued until killing. All animals were injected with p $\alpha$-tTA ( $5 \mu \mathrm{g})$, pUHC13-3 (5 $\mu \mathrm{g})$, and pRSVCAT $(2 \mu \mathrm{g}) .5 \mathrm{~d}$ later, normalized luciferase activity was determined as above. Each data point represents the mean \pm SE. Compared with animals receiving no antibiotic, normalized luciferase activity was repressed in a dose-dependent manner with both $0.1(P<0.005)$ or 1.0 $\mathrm{mg} / \mathrm{ml}(P<0.001)$ tetracycline hydrochloride.
As shown in Fig. $4 \mathrm{~B}, 24 \mathrm{~h}$ after removing a submaximally inhibitory dose $(0.1 \mathrm{mg} / \mathrm{ml})$ of tetracycline from the drinking water, reporter gene activity had increased 2.5 -fold and was fully induced by $60 \mathrm{~h}(P<0.0001)$.

To account for time-dependent changes in reporter gene activity associated with the gene-transfer technique, ratios of normalized luciferase activity in the experimental groups (repressed or induced) to those observed in the respective control groups were derived at each time point. The temporal profile of tetracycline-regulated gene repression and induction achieved in vivo were then compared directly, as shown in Fig. 4 C. In both cases, substantial modulation of gene expression was evident within $24 \mathrm{~h}$ after manipulating antibiotic therapy and approached new steady state levels within about $48 \mathrm{~h}$.

\section{Discussion}

In this report, we have demonstrated the feasibility of achieving highly regulated transcriptional control of foreign genes introduced in vivo. First, we have shown that a chimeric protein (tTA), consisting of the DNA and antibiotic binding domains from the tet $\mathrm{R}$ protein fused to the transactivation domain of herpes simplex VP16, can successfully transactivate a reporter gene harboring tet $\mathrm{O}$ sequences in vivo. Second, we have demonstrated that oral therapy with tetracycline can regulate effectively the extent of transactivation over several orders of magnitude. Finally, we have defined the time course of target gene induction and repression in response to tetracycline treatment and have shown that this process is relatively rapid.

Few mechanisms for controlling gene expression in vivo have been described, and to date none have demonstrated the temporal and quantitative regulation characteristic of the tTA system. Binary transgenic approaches, in which transactivator strains of mice harboring the yeast GAL4 protein are crossed with second strains harboring a GAL4-inducible target gene, have recently been described (8). In progeny carrying both transgenes, the normally silent target gene was activated by the presence of the transactivator. Although target gene activation in compound hemizygous offspring could be specifically activated, the extent of transactivation was not responsive to external regulation. Approaches based upon the Drosophila ecdysone receptor have also been proposed for regulated expression of target genes, however, to date only in vitro studies have been reported (9). By fusing the ligand-binding domain of the insect hormone receptor to the DNA-binding domain of heterologous transcription factors, hormone-dependent transcription of reporter genes flanked by ecdysone response elements was demonstrated. Target gene expression in vitro could be induced $\sim 50$-fold by the addition of micromolar concentrations of muristerone A. Finally, modified proteins derived from the lac repressor have also been constructed which transactivate target genes harboring lac operator sequences. The lacI activator protein LAP267, containing the transactivation domain of herpes simplex virus VP16 inserted into the lac repressor, results in a temperature- and isopropyl- $\beta$-D-thiogalactopyranoside-sensitive transactivator. Although selected cell lines showed induction of target gene expression up to 1,200-fold, the requirement for stringent temperature control and millimolar concentrations of isopropyl- $\beta$-D-thiogalactopyranoside is potentially problematic for in vivo use (10).

The in vivo regulatory system described in this report uses derivatives of polycyclic naphthacenecarboxamides (11). The 
A

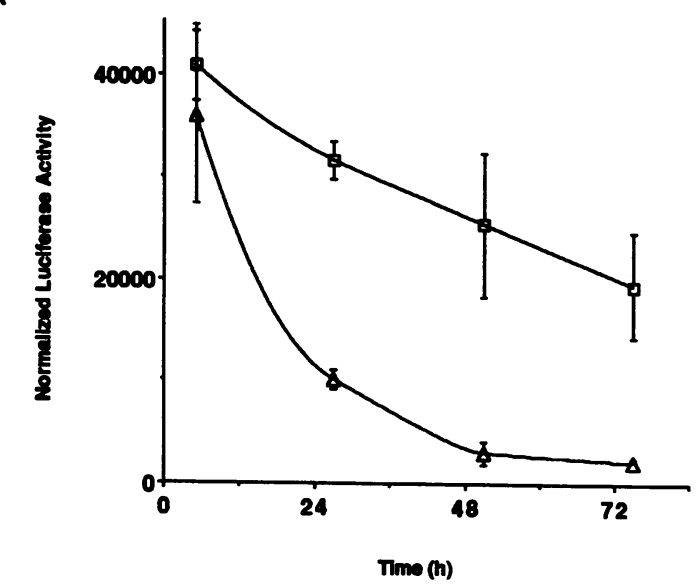

B

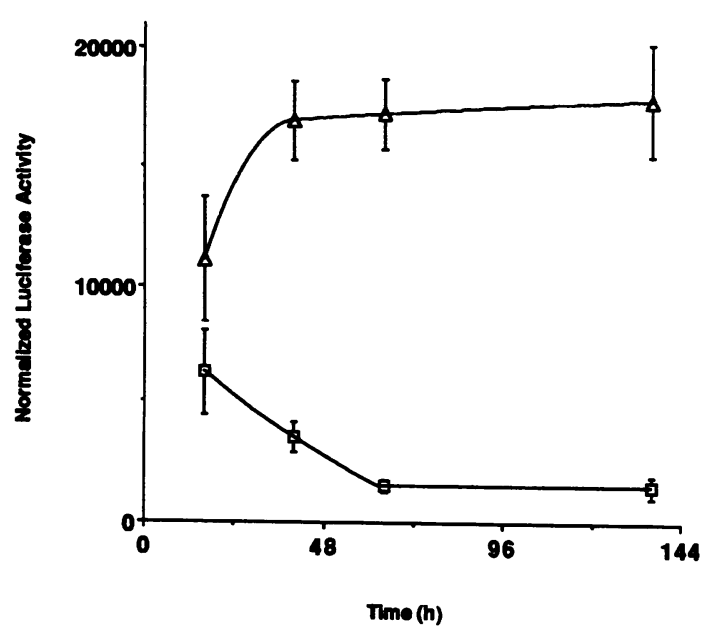

c

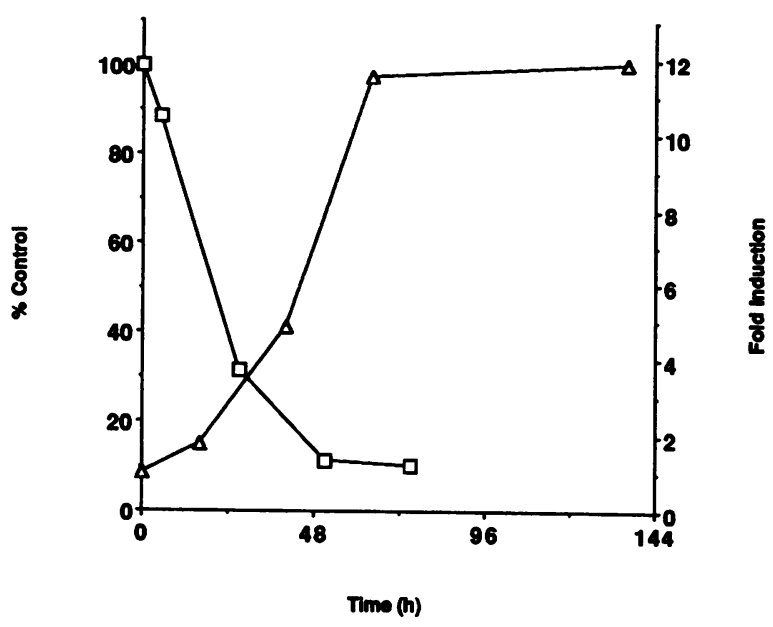

Figure 4. Kinetic analysis of tetracycline-regulated expression. ( $A$ ) Repression of gene expression. 40 rats underwent direct cardiac gene transfer with p $\alpha$-tTA, pUHC13-3, and pRSVCAT. $5 \mathrm{~d}$ later, half the animals were randomly chosen to receive antibiotic treatment (repressed, open triangles) or vehicle alone (control, open squares). At each time point, hearts from at least four animals from each group were excised, and normalized luciferase activity was determined. Data points are presented as the mean $\pm S E$ for each group at each time point. $(B)$ Derepression of gene expression. 40 rats were pretreated with $0.1 \mathrm{mg} / \mathrm{ml}$ tetracycline in their drinking water, beginning $2 \mathrm{~d}$ before cardiac gene transfer with p $\alpha$-tTA, pUHC13-3, and tetracyclines have several known toxic effects in mammals, particularly in the developing skeleton and teeth, thus it is important to note that the dosages required to inhibit tTA-dependent transcription are low (11-13). Drinking water containing 0.1 $\mathrm{mg} / \mathrm{ml}$ tetracycline hydrochloride is only $10 \%$ of the normal therapeutic dosage in rodents, yet is sufficient to inhibit target gene expression by $90 \%$ (14). Assuming similar pharmacokinetics in humans, gene therapies incorporating tetracycline regulation could be envisioned which carry little additional morbidity as compared with unregulated systems. Conceivably, analogues with greater potency than tetracycline (11) could be substituted which are effective at even lower doses with less potential toxicity. In addition, analogues that are biometabolized more rapidly than tetracycline hydrochloride could be used, which should allow for more rapid gene induction upon drug withdrawal. Finally, the abundance of target gene products with half-lives shorter than the luciferase enzyme, estimated to be $\sim 3 \mathrm{~h}$, would be expected to respond even more rapidly to alterations in tetracycline administration (15).

Injection of the tTA-dependent transcription unit generated low levels of luciferase activity ( $0.8 \%$ of maximum), even in the absence of a coinjected transactivator expression plasmid. This could represent cryptic transcription initiation from within the plasmid backbone or leakiness from the chimeric tet operator/CMV minimal promoter. Even this relatively low level of transcription could be deleterious in applications requiring stringent on-off control. The transactivator-independent activity seen with pUHC13-3 was reduced by $45 \%$ (data not shown) by placing the polyadenylation addition signals from the SV40 early genes upstream of the chimeric promoter, suggesting that both mechanisms may contribute to this background activity.

The tight control of gene expression demonstrated in this in vivo model may have wide applicability. In combination with gene transfer techniques which result in prolonged or stable expression in vivo, including the use of viral vectors, direct injection of naked or complexed DNA, as well as germ-line transfer into transgenic animals (16-23), this system should allow for the rapid and reversible titration of gene product abundance appropriate for the desired biological effect. This approach may be particularly useful in the study of biological processes such as cardiac hypertrophy, in which many of the observed alterations in gene expression are quantitative rather than qualitative. Furthermore, localized or cell type-specific expression and regulation of genes of interest could be obtained

pRSVCAT. $5 \mathrm{~d}$ after gene transfer, half the animals were switched to vehicle alone (induced, open triangles), and half were continued on tetracycline (control, open squares). At each time point, hearts from at least four animals from each group were excised, and normalized luciferase activity was determined. Data points are presented as the mean \pm SE for each group at each time point. $(C)$ Temporal profile of tetracycline-regulated gene expression. Data points are derived from $A$ and $B$ and are presented as the ratio of the normalized luciferase values in the repressed or induced groups to values obtained in their respective controls. A decline in normalized luciferase activity is evident within hours after initiating tetracycline treatment, falling to $\sim 40 \%$ of control levels at $24 \mathrm{~h}$ (open squares). These differences are statistically significant $(P<0.01)$ at 27,51 , and $75 \mathrm{~h}$. Normalized luciferase activity rises progressively after stopping tetracycline treatment and peaks at $\sim 12$-fold induction (open triangles). These differences are statistically significant $(P<0.01)$ at 40,64 , and $136 \mathrm{~h}$. 
by either introducing the foreign DNA in a distinct anatomical region, such as a segment of the vasculature $(24,25)$, or by expressing tTA under the control of tissue-specific or developmentally regulated promoters, as demonstrated here. Tetracycline-regulated gene expression could conceivably be incorporated into current gene therapy strategies. In addition to direct in vivo gene transfer approaches, cells such as skeletal myoblasts, hepatocytes, or vascular endothelial cells could be transduced ex vivo (26-30), tested for appropriate regulation of the gene of interest, and reimplanted to provide a controlled source of a locally active or secreted gene product.

\section{Acknowledgments}

We thank C. Branigan for technical assistance; M. Gossen and H. Bujard for the gift of plasmids pUHC13-3 and pUHD15-1; and Leslie A. Leinwand for continued support.

This work was supported in part by a National Institutes of Health Physican Scientist Award HL-02391 to G. I. Fishman and HL-46034 to P. M. Buttrick.

\section{References}

1. Gossen, M., and H. Bujard. 1992. Tight control of gene expression in mammalian cells by tetracycline-responsive promoters. Proc. Natl. Acad. Sci. USA. 89:5547-5551.

2. Kitsis, R. N., P. M. Buttrick, E. M. McNally, M. L. Kaplan, and L. A. Leinwand. 1991. Hormonal modulation of a gene injected into rat heart in vivo. Proc. Natl. Acad. Sci. USA. 88:4138-4142.

3. Mahdavi, V., A. P. Chambers, and B. Nadal-Ginard. 1984. Cardiac $\alpha$ - and $\beta$-myosin heavy chain genes are organized in tandem. Proc. Natl. Acad. Sci. USA. $81: 2626-2630$.

4. DeNolo, F. M., D. D. Moore, and H. M. Goodman. 1981. Human growth hormone DNA sequence and mRNA structure: possible alternative splicing. $\mathrm{Nu}$ cleic Acids Res. 9:3173-3179.

5. Gorman, C. M., G. T. Merlino, M. C. Willingham, I. Pastan, and B. H. Howard. 1982. The Rous sarcoma virus long terminal repeat is a strong promoter when introduced into a variety of eukaryotic cells by DNA-mediated transfection. Proc. Natl. Acad. Sci. USA. 79:6777-6781.

6. Ausubel, F. M., R. Brent, R. E. Kingston, D. D. Moore, J. G. Seidman, J. A. Smith, and K. Struhl, editors. 1987. Current Protocols in Molecular Biology. Wiley Interscience, New York.

7. Buttrick, P. M., M. L. Kaplan, R. N. Kitsis, and L. A. Leinwand. 1993. Distinct behavior of cardiac myosin heavy chain gene constructs in vivo. Discordance with in vitro results. Circ. Res. 72:1211-1217.

8. Ornitz, D. M., R. W. Moreadith, and P. Leder. 1991. Binary system for regulating transgene expression in mice: targeting int-2 gene expression with yeast GAL4/UAS control elements. Proc. Natl. Acad. Sci. USA. 88:698-702.

9. Christopherson, K. S., M. R. Mark, V. Bajaj, and P. J. Godowski. 1992 Ecdysteroid-dependent regulation of genes in mammalian cells by a Drosophila ecdysone receptor and chimeric transactivators. Proc. Natl. Acad. Sci. USA. 89:6314-6318

10. Baim, S. B., M. A. Labow, A. J. Levine, and T. Shenk. 1991. A chimeric mammalian transactivator based on the lac repressor that is regulated by temperature and isopropyl- $\beta$-D-thiogalactopyranoside. Proc. Natl. Acad. Sci. USA. 88:5072-5076.

11. Sande, M. A., and G. L. Mandell. 1990. Tetracycline, chloramphenicol, erythromycin and miscellaneous antibiotic agents. In Goodman and Gilman's
The Pharmacological Basis of Therapeutics., A. G. Gilman, T. W. Rall, A. S. Nies, and P. Taylor, editor. Pergamon Press, New York. 1117-1125.

12. Toxicology and Carcinogenesis Studies of Tetracycline Hydrochloride in F344/N Rats and B6C3F1 Mice. 1989. D. D. Deitz, editor. National Institutes of Health Publication 89-2600. 172 pp.

13. Dietz, D. D., K. M. Abdo, J. K. Haseman, S. L. Eustis, and J. E. Huff. 1991. Comparative toxicity and carcinogenicity studies of tetracycline and oxytetracycline in rats and mice. Fundam. Appl. Toxicol. 17:335-346.

14. Russell, R. J. 1979. A Guide to Diagnosis, Treatment and Husbandry of Pet Rabbits and Rodents. Veterinary Medicine Publishing Co., Bonner Springs, KS. $61 \mathrm{pp}$.

15. Thompson, J. F., L. S. Hayes, and D. B. Lloyd. 1991. Modulation of firefly luciferase stability and impact on studies of gene regulation. Gene (Amst.). 103:171-177.

16. Ho, D. Y., and E. S. Mocarski. 1988. $\beta$-galactosidase as a marker in the peripheral and neural tissues of the herpes simplex virus-infected mouse. Virology 167:279-283.

17. Dobson, A. T., F. Sederati, G. Devi-Rao, W. M. Flanagan, M. J. Farrell, J. G. Stevens, E. K. Wagner, and L. T. Feldman. 1989. Identification of the latency-associated transcript promoter by expression of the rabbit beta-globin mRNA in mouse sensory nerve ganglia infected with a recombinant herpes simplex virus. J. Virol. 63:3844-3851.

18. Miller, A. D. 1992. Human gene therapy comes of age. Nature (Lond.). 357:455-460.

19. Rosenfeld, M. A., W. Siegfried, K. Yoshimura, K. Yoneyama, M Fukayama, L. E. Stier, P. K. Paakko, P. Gilardi, L. D. Stratford-Perricaudet, and M. Perricaudet. 1991. Adenovirus-mediated transfer of a recombinant alpha 1antitrypsin gene to the lung epithelium in vivo. Science (Wash. DC). 252:431434.

20. Stratford-Perricaudet, L. D., I. Makeh, M. Perricaudet, and P. Briand. 1992. Widespread long-term gene transfer to mouse skeletal muscles and heart. $J$. Clin. Invest. 90:626-630.

21. Wolff, J. A., R. W. Malone, P. Williams, W. Chong, G. Acsadi, A. Jani, and P. L. Felgner. 1990. Direct gene transfer into mouse muscle in vivo. Science (Wash. DC). 247:1465-1468.

22. Zhu, N., D. Liggitt, Y. Liu, and R. Debs. 1993. Systemic gene expression after intravenous DNA delivery into adult mice. Science (Wash. DC). 261:209211.

23. Brinster, R. L., M. Y. Chen, M. E. Trumbauer, A. W. Sevear, R. Warren, and R. D. Palmiter. 1981. Somatic expression of MSU-TU in mice following injection of a fusion gene into eggs. Cell. 27:223-231.

24. Acsadi, G., G. Dickson, D. R. Love, A. Jani, F. S. Walsh, A. Gurusinghe, J. A. Wolff, and K. E. Davies. 1991. Human dystrophin expression in mdx mice after intramuscular injection of DNA constructs. Nature (Lond.) 352:815-818.

25. Nabel, E. G., G. Plautz, and G. J. Nabel. 1990. Site-specific gene expression in vivo by direct gene transfer into the arterial wall. Science (Wash. DC). 249:1285-1288.

26. Nabel, E. G., G. Plautz, F. M. Boyce, J. C. Stanely, and G. J. Nabel. 1989. Recombinant gene expression in vivo within endothelial cells of the arterial wall. Science (Wash. DC). 244:1342-1344.

27. Chowdury, J. R., M. Grossman, S. Gupta, N. R. Chowdury, J. R. Baker, Jr., and J. M. Wilson. 1991. Long-term improvement of hypercholesterolemia after ex vivo gene therapy in LDLR-deficient rabbits. Science (Wash. DC). 254:1802-1805.

28. Dhawan, J., L. C. Pan, G. K. Pavlath, M. A. Travis, A. M. Lanctot, and H. M. Blau. 1991. Systemic delivery of human growth hormone by injection of genetically engineered myoblasts. Science (Wash. DC). 254:1509-1512.

29. Yao, S. N., J. M. Wilson, E. G. Nabel, S. Kurachi, H. L. Hachiya, and K. Kurachi. 1991. Expression of human factor IX in rat capillary endothelial cells: toward somatic gene therapy for hemophilia B. Proc. Natl. Acad. Sci. USA. 88:8101-8105.

30. Jiao, S., V. Gurevich, and J. A. Wolff. 1993. Long-term correction of rat model of Parkinson's disease by gene therapy. Nature (Lond.). 362:450-453. 